PNL-7734

UC-700

$2 F$

\title{
Use of the TRUEX Process for the Pretreatment of Neutralized Cladding Removal Waste (NCRW) Sludge - Results of a Design Basis Experiment
}

\section{J. L. Swanson}

July 1991

Prepared for the U.S. Department of Energy under Contract DE-AC06-76RLO 1830

Pacific Northwest Laboratory Operated for the U.S. Department of Energy by Battelle Memorial Institute 


\title{
DISCLAIMER
}

This report was prepared as an account of work sponsored by an agency of the United States Government. Neither the United States Government nor any agency thereof, nor Battelle Memorial Instikute, nor any of their employees, makes any warranty, expressed or implied, of assumes any legal liability or responsibility for the accuracy, completeness, or usefulness of any information, apparatus, product, or process disclosed, or represents that its use would not infringe privately owned rights. Reference herein to any specific commercial product, process, or service by irade name, trademark, manufacturer, or olherwise does not necessarily constitute or imply its endorsement, recommendation, or favoring by the United States Government or any agency thereof, or Battelle Memorial Institute. The views and opinions of authors expressed herein do not necessarily state or reflect those of the United States Government or any agency thereof.

\author{
PACIFIC NORTHWEST LABORATORY \\ operated by \\ BATTELLE MEMORIAL INSTITUTE \\ for the \\ UNITEO STATES DEPARTMENT OF ENERGY \\ under Contract DE-ACO6-76RLO 1830
}

Printed in the United States of America

Available to DOE and DOE contractors from the

Office of Scientific and Technical Information, P.O. Box 62, Oak Ridge, IN 37831; prices available from (615) 576-8401. FTS 626-8401.

Available to the puhlic from the National Technical Information Service, U.5. Department of Commerce, 5285 Port Royal Rd., Springfield, VA 22161. 
PNL -7734

UC -700

\section{3}

USE OF THE TRUEX PROCESS FOR THE PRETREATMENT OF NEUTRALIZED CLADDING REMOVAL WASTE (NCRW) SLUDGE RESULTS OF A DESIGN BASIS EXPERIMENT

J. L. Swanson

July 1991

Prepared for

the U.S. Department of Energy

under Contract DE-AC06-76RL0 1830

Pacific Northwest Laboratory

Richland, Washington 99352 



\section{SUMMARY}

This report presents the results of an experiment designed to demonstrate the feasibility of a sludge dissolution/solvent extraction process to separate transuranic elements from the bulk components of Hanford neutralized cladding removal waste (NCRW) sludge. Such a separation would allow the bulk of the waste to be disposed of as low-level waste, which is much less costly than geologic disposal as would be required for the waste in its current form. The results indicate that the proposed process is well suited to meet the desired objectives.

A composite sample of NCRW sludge taken from Tank 103-AW in 1986 was dissolved in nitric acid at room temperature. Dissolution of bulk components and a1l radionuclides was $\geq 95 \%$ complete; thus, $\leq 5 \%$ of the bulk components will require geologic disposal.

The TRUEX (IRansuranium EXtraction) solvent extraction process gave very good separation of the transuranic elements from the bulk components of the waste. The alpha activity remaining in the bulk component stream was lowered to $-0.1 \mathrm{nCi} / \mathrm{mL}$, which is well below the low-level waste limit of $100 \mathrm{nCi} / \mathrm{g}$. The transuranic element stream was well purified from the bulk components of the waste, by a factor of $-3 \times 10^{4}$ for zirconium and fluoride and an even greater factor for sodium; thus, the bulk component content of the TRUEX product stream (which will require geologic disposal) is small in comparison with that of the undissolved residue. 



\section{ACKNOHLEDGMENTS}

Funding for this work was provided by Westinghouse Hanford Company through the Waste Pretreatment Technology Group managed by J. N. Appe1. The cognizant engineer was S. A. Barker; his assistance and cooperation are especially appreciated.

J. M. Deal performed most of the laboratory work and G. J. Lumetta provided valuable review and consultation. Members of the analytical laboratory who contributed significant support were D. E. Rinehart, C. 0. Harvey, and S. H. Thompson. B. O. Barnes provided invaluable assistance on the quality assurance aspects of the work.

The report was edited by Kelly Parnell and the text processing was done by Paulette Goodenough, Anita Lebold, Lisa Schwegel, and Annette Taylor. 
. 


\section{CONTENTS}

SUMMARY .................... $\mathbf{i} \mathbf{i} \mathbf{i}$

ACKNOWLEDGMENTS ...................

1.0 INTRODUCTION $\ldots \ldots \ldots \ldots \ldots \ldots$

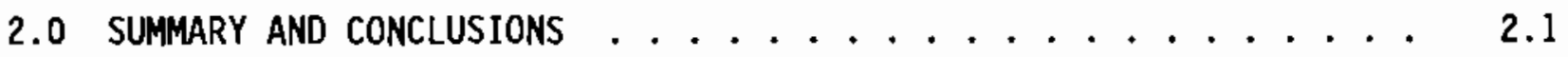

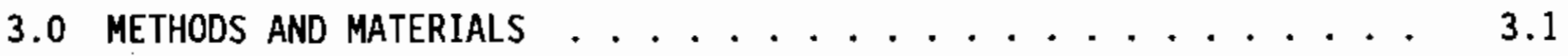

3.1 SLUDGE SAMPLE $\ldots \ldots \ldots \ldots . \ldots \ldots . \ldots \ldots$

3.2 DISSOLUTION AND FILTRATION $\ldots \ldots \ldots \ldots . \ldots . \ldots . \ldots$

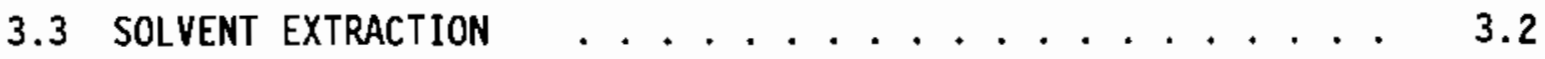

3.4 ANALYTICAL METHODS $\ldots \ldots \ldots . \ldots . \ldots . \ldots . \ldots$

4.0 RESULTS AND DISCUSSION . . . . . . . . . . . 4.1

4.1 DISSOLUTION RESULTS . . . . . . . . . . . . 4.1

4.2 SOLVENT EXTRACTION RESULTS $\ldots \ldots \ldots . \ldots . \ldots . \ldots$

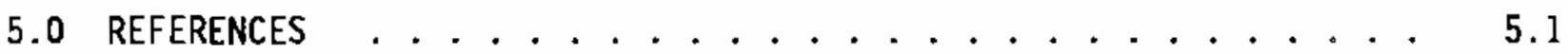




\section{FIGURES}

4.1 Flowsheet Simulated in Design Basis Experiment . . . . . . . 4.2

\section{TABLES}

3.1 Elements, Detection Limits, and Interferences for ICP

Analyses ...................... 3.4

4.1 Distribution of Nonradioactive Metals in Sludge Dissolution step ...................... 4.4

4.2 Distribution of Radionuclides in Sludge Dissolution Step . . . . 4.5

4.3 Composition of Undissolved Residue Relative to Glass Plant Feed Specifications .................. . . 4.6

4.4 Solvent Extraction Contacts Performed . . . . . . . . . . . . 4.9

4.5 Solvent Extraction Results . . . . . . . . . . . . . . . 4.10

4.6 Acid and Fluoride Material Balances in Solvent Extraction Contacts ...................... . 4. 44

4.7 Additional Radionuclide Concentration Data for Solvent Extraction Samples ................. 4.16

4.8 Additional ICP Data for Solvent Extraction Samples . . . . . . . 4.17 


\subsection{INTRODUCTION}

One of the unique types of radioactive waste currently being stored at Hanford is neutralized cladding removal waste (NCRW) sludge. This sludge contains large amounts of zirconium and sodium compounds, primarily hydroxides and fluorides, with smaller amounts of potassium, nitrite, and other materials. NCRW sludge also contains uranium, the transuranics (TRUs) plutonium and americium, and a mixture of fission products typical of the nonvolatiles present in irradiated reactor fuel.

This waste arose as a result of the method used to process the zirconium alloy-clad, metallic uranium fuel elements that were irradiated in $\mathrm{N}$ Reactor at Hanford. That method involved dissolution of the cladding in ammonium fluoride solution followed by a separate dissolution of the uranium in nitric acid. Because the ammonium fluoride solution also attacked the uranium, a portion (generally $-3 \%$ ) of the uranium (and its contained TRUs and fission products) dissolved in the decladding step along with the zirconium alloy. Most of the reacted uranium and TRUs were recovered as fluoride precipitates, which were metathesized (with potassium hydroxide solution) to hydroxide precipitates before the acid dissolution step. The metathesis was done to lower the amount of fluoride in the dissolved uranium solution.

The spent decladding and metathesis solutions (plus the subsequent rinse solutions) were then adjusted for storage in underground, carbon steel-1ined tanks. To protect these tanks against corrosion, this adjustment involved raising the $\mathrm{pH}$ with sodium hydroxide solution and adding nitrite ion (as the sodium salt). These additions led to the precipitation of zirconium hydroxide and sodium fluoride compounds, which then formed a sludge layer in the underground tank. Supernate solution was periodically removed from above the settled sludge and then transferred to other tanks to make room for additional sludge. The NCRW sludge in its current form thus contains only portions of the soluble or partially soluble components that were added (e.g., sodium, fluoride, hydroxide, nitrite) along with all of the insoluble components (e.g., zirconium, plus a small fraction of the uranium and TRUs that were not recovered in the decladding and metathesis operations). 
The concentration of TRU elements in this sludge gives an alpha activity of $-10^{3} \mathrm{nCi} / \mathrm{g}$ sludge, which is too high to allow this waste to be disposed of as low-level waste (LLW). Disposal of this waste in a geologic repository would be more costly than disposal as LLW. Thus, an incentive exists to treat this waste to separate the TRUs from the bulk components so that the bulk components can be disposed of as LLW with only a small volume of TRUcontaining fraction requiring geologic disposal (e.g., in a vitrified form).

To study the feasibility of various methods to accomplish such a separation of the TRUs from the bulk components of NCRW sludge, Westinghouse Hanford Company (Westinghouse Hanford) has provided support to Pacific Northwest Laboratory $(\mathrm{PNL})^{(a)}$ for an experimental program to determine the effectiveness of various methods. The results obtained during the first several years of this program have recently been published (Swanson 1991). The early portion of this study examined approaches such as differences in settling rates and selective leaching of the TRUs away from the bulk solids; these approaches did not give the needed separations. The study then centered on an approach involving nitric acid dissolution of the sludge followed by the use of the TRUEX (IRans Uranium EXtraction) solvent extraction process for separation of the TRUs from the inert components of the sludge. This approach gave very promising results in preliminary experiments; Westinghouse Hanford then requested that a "design basis experiment" be performed as a demonstration of integrated sludge dissolution and soivent extraction steps. This report contains the results of that experiment, which was completed early in fiscal year 1991.

(a) Pacific Northwest Laboratory is operated by Battelle Memorial Institute for the U.S. Department of Energy under Contract DE-ACO6-76RLO 1830. 


\subsection{SUMMARY AND CONCLUSIONS}

This report presents the resuits of an experiment designed to demonstrate the feasibility of a sludge dissolution/solvent extraction process to separate transuranic elements from the bulk components of Hanford NCRW sludge. Such a separation would allow the bulk of the waste to be disposed of as LLW, which is much less costly than geologic disposal as would be required for the waste in its current form. The results indicate that the proposed process is well suited to meet the desired objectives.

A composite sample of NCRW sludge taken from Tank 103-AW in 1986 was dissolved in nitric acid at room temperature. Dissolution of major components and a 11 radionuclides was $\geq 95 \%$ complete; markedly less complete dissolution of aluminum and phosphorus was obtained. These two elements might pose a problem in subsequent vitrification of the undissolved residue.

The TRUEX solvent extraction process gave very good separation of the transuranic elements from the bulk components of the waste. The alpha activity remaining in the bulk component stream was lowered to $-0.1 \mathrm{nCi} / \mathrm{mL}$, which is well below the LLW limit of $100 \mathrm{nCi} / \mathrm{g}$. The transuranic element stream was well purified from the bulk components of the waste, by a factor of $-3 \times 10^{4}$ for zirconium and fluoride and an even greater factor for sodium. Materials that followed the TRUs through the process were uranium and rare earth elements such as lanthanum, which had been added to the waste, and fission products such as cerium and europium.

The results of this experiment demonstrate the feasibility of the proposed process. However, work is continuing to optimize the process. Important areas of study include 1) factors affecting precipitation from feed solutions and the formation of interfacial cruds, and 2) development of alternative transuranic stripping conditions to minimize the addition of phosphate to the transuranic stream. The study of factors affecting precipitation and interfacial crud formation is especially important now that it appears that the sludge will be removed from the tanks in layers that are not of uniform composition rather than as a composite mixture. 


\subsection{METHODS AND MATERIALS}

The information in this section describes the materials, the procedures, and the analytical methods used in this experiment.

\subsection{SLUDGE SAMPLE}

The sample of sludge used in this experiment was a composite of the segments obtained when Tank 103-AW was core sampled in 1986. This composite was prepared by mixing approximately equal portions of segments 3 through 9 . Based on earlier analysis of these segments, the composite contained $-500 \mathrm{nCi}$ of plutonium plus americium alpha activity per gram of moist sludge. This moist composite had gradually dried out during storage and appeared quite dry when used here. Other results indicate that the sludge lost about half its weight during the drying process. The quantity of air-dried sludge used in this experiment was $2.45 \mathrm{~g}$.

\subsection{DISSOLUTION AND FILTRATION}

The air-dried sludge was first soaked in water for several days; a total of $19 \mathrm{~mL}$ of water was added, with $0.5 \mathrm{~mL}$ of supernate being removed for measurements that were not part of this design basis experiment. Nitric acid ( $3.8 \mathrm{~mL}$ of 15.7 M) was then added dropwise to the stirred s7urry, and stirring was continued for $-2 \mathrm{~h}$ at room temperature $\left(-23^{\circ} \mathrm{C}\right)$. The volume of solution plus undissolved residue was then estimated to be $22.9 \mathrm{~mL}$; this estimation was based on the weight of the water required to give the same liquid level in an identical container.

The dissolved sludge solution was clarified by vacuum filtration using a packaged filter assembly (Nalge Company) containing a $0.2-\mu m$ filter, and the residual solids (and the filter assembly) were then rinsed with $2 \mathrm{~mL}$ of $0.3 \underline{M}$ $\mathrm{HNO}_{3}$. This rinse was added to the dissolved sludge solution in the reservoir of the filter assembly and (nearly all of) the mixture was poured from the reservoir into storage vials. The total volume of this solution in the storage vials was estimated (as before) to be $23.6 \mathrm{~mL}$. 
The residual solids were next washed several times with 4-mL portions of water. These washes were pulled (by vacuum) into the same reservoir from which the dissolved sludge solution had been poured.

The washed residue from the dissolution step was then slurried off the filter (with water), and the stirred slurry was divided into two portions to be dissolved for various analyses. One portion was dissolved by adding hydrochloric acid to a concentration of $-1.3 \mathrm{M}$ and hydrofluoric acid to a concentration of $\sim 0.4 \mathrm{M}$ and heating at $\sim 100^{\circ} \mathrm{C}$ for $2 \mathrm{~h}$; portions of this solution were diluted and analyzed for sulfate, phosphate, and total organic carbon (TOC). The other portion of the washed residue was adjusted to $\sim 3 \mathrm{M} \mathrm{HNO}_{3}$ and $-0.2 \mathrm{M} \mathrm{H}_{2} \mathrm{C}_{2} \mathrm{O}_{4}$ and heated at $-100^{\circ} \mathrm{C}$ for $2 \mathrm{~h}$; portions of this solution were diluted and analyzed for metal ions, fluoride ions, and alpha- and gammaemitting radionuclides. A slight turbidity existed in this second solution, but this should have had no significant impact on the analytical results because the sample and the dilutions were mixed prior to analysis so that the material causing the turbidity was included in the analytical sample.

\subsection{SOLVENT EXTRACTION}

To prepare feed for the solvent extraction process, $8.83 \mathrm{~mL}$ of water and $0.63 \mathrm{~mL}$ of $15.7 \mathrm{M} \mathrm{HNO}_{3}$ were added to $15.0 \mathrm{~mL}$ of the dissolved sludge solution; this was done 2 days after the dissolution step, at which time visible solids had not yet formed in the dissolved sludge solution. A total of $0.35 \mathrm{~mL}$ of this mixture was removed in analytical samples, $0.24 \mathrm{~mL}$ of $1 \mathrm{M} \mathrm{H}_{2} \mathrm{C}_{2} \mathrm{O}_{4}$ was added, and then $8.00 \mathrm{~mL}$ of carbonate-washed TRUEX solvent was added and the first contact was performed. The TRUEX solvent used here was obtained from Westinghouse Hanford; it contained $0.2 \mathrm{M}$ CMPO $+1.4 \mathrm{M}$ TBP in NPH diluent. [CMPO is the abbreviation commoniy used for the compound octyl (phenyl) - N, Ndiisobutylcarbamoylmethylphosphine oxide; TBP is the abbreviation used for the compound n-tributyl phosphate; NPH denotes a mixture of normal paraffin hydrocarbons.]

Portions of both the organic and aqueous phases were then subjected to additional contacts. The aqueous phase from the first contact was extracted twice more with fresh solvent; the organic phase from the first contact was 
scrubbed six times (twice with $1.5 \underline{\mathrm{MHNO}}+0.05 \mathrm{M} \mathrm{H}_{2} \mathrm{C}_{2} \mathrm{O}_{4}$, twice with $2.3 \underline{M}$ $\mathrm{HNO}_{3}$, and twice with water), was then stripped three times with $0.21 \mathrm{MHEDPA}$, and was then washed with $0.25 \mathrm{M} \mathrm{Na}_{2} \mathrm{CO}_{3}$ solution. (HEDPA is the abbreviation commonly used for the compound 1-hydroxyethane-1,1-diphosphonic acid; this compound was also obtained from Westinghouse Hanford.) The scrub and strip solutions used in these contacts were standardized by titration with standard sodium hydroxide solution.

The solvent extraction contacts were performed in glass vials. The vials were shaken manually for $0.5 \mathrm{~min}$ and were then centrifuged for 1 min to effect good phase separation. Portions of phases were then transferred to new vials for the subsequent contacts. A time period of $1.5 \mathrm{~h}$ was required to complete the 13 contacts done in this work; dilutions of each phase were then made over the next several hours, for later analysis. Except for the last contact where 76-fold dilutions were made, the dilution factor was 151 .

Several dilutions were made of each phase. One dilution was made with water for acid and fluoride analyses, and two dilutions were made with ditute nitric acid: one for radiochemical analyses and one for inductively coupled plasma (ICP) determination of nonradioactive elements. Addition of organic samples to aqueous solutions is, of course, not really a dilution. However, these organic "dilutions" were well mixed both immediately after preparation and later while aliquots were removed for analysis; this mixing would strip $>90 \%$ of any species having a distribution coefficient (the species concentration in the organic phase divided by its concentration in the aqueous phase) of $<17$ at the dilute acid concentrations of the dilutions. Thus, these organic phase "dilutions" should provide valid data even if the aliquot removed for analysis might not contain the same proportions of organic and aqueous phases as in the initial "dilution."

\subsection{ANALYTICAL METHODS}

The concentrations of nonradioactive metal ions were determined by ICP analysis. Table 3.1 lists the elements that the instrument was programmed to measure, their indicated detection limits (in the dilution being analyzed), and the magnitude of the interferences caused by the presence of zirconium or 
TABLE 3.1. Elements, Detection Limits, and Interferences for ICP Analyses

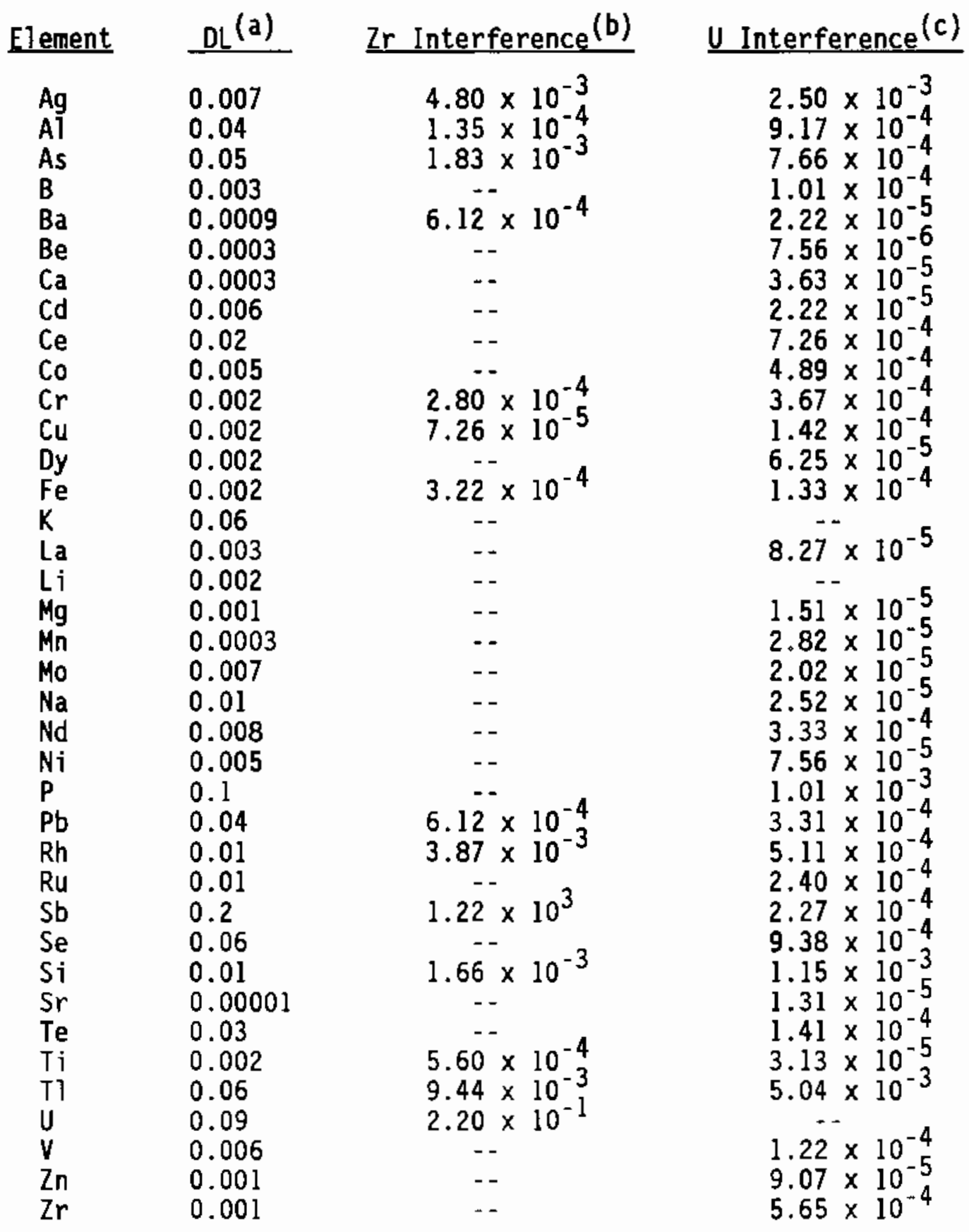

(a) Optimum detection limit, in $\mathrm{mg} / \mathrm{L}$.

(b) Subtract these values per gram of zirconium present to get gram of element actually present.

(c) Subtract these values per gram of uranium present to get gram of element actually present. 
uranium. The most important interference by far in the samples analyzed here was that of zirconium on uranium, although the interference of uranium on severai elements was important in analysis of the strip solutions, in which uranium was the predominant metal ion. The ICP data for some elements were a] so subject to a blank correction because of the presence in the dilution solution of aluminum, calcium, sodium, and silicon at $\sim 0.3 \mathrm{mg} / \mathrm{L}$ and of iron and zinc at $-0.03 \mathrm{mg} / \mathrm{L}$.

Gamma-emitting radionuclide concentrations were determined by counting $10-\mathrm{mL}$ portions of the dilutions and of a separate dilution of the washed organic phase. Analyses for alpha-emitting radionuclides involved the counting of $0.1-\mathrm{mL}$ dried mounts of the sample dilutions and of the undiluted, washed organic phase. Alpha energy analyses were performed on selected mounts to differentiate the ${ }^{241}$ Am plus ${ }^{238} \mathrm{Pu}$ activity from the ${ }^{239} \mathrm{Pu}$ plus ${ }^{240} \mathrm{Pu}$ activity. The ${ }^{238} \mathrm{Pu}$ activity in the composite sludge sample used in this experiment amounted to $-7.5 \%$ of the ${ }^{239} \mathrm{Pu}$ plus ${ }^{240} \mathrm{Pu}$ activity; this proportion was used to calculate the true total plutonium and americium activities.

Phosphate and sulfate contents of the (initially) undissolved residue were determined with an ion chromatograph, using a water dilution of the hydrochloric/hydrofluoric acid mixture that had been used to dissolve the residue. Total organic carbon analysis was done using a carbon analyzer instrument.

The sums of the nitric and hydrofluoric acid concentrations were determined by titrating $4-\mathrm{mL}$ aliquots of the dilutions with standard $0.1 \mathrm{M} \mathrm{NaOH}$ solution, and then correcting these values for the contributions of hydroTyzable metal ions and of oxalic acid (if present). The end points of these titrations were taken to be at $\mathrm{pH}=7$ except for the HEDPA strip solutions, where $\mathrm{pH}=5$ was used. The hydrolyzable metal ion concentrations were based on the ICP analyses, and the oxalic acid concentrations were estimated from the amounts added and the distribution coefficient values given by Horwitz et al. (1985). The hydrolyzable ions were generally assumed to contribute two moles of acid per mole of zirconium and uranium and three moles of acid per mole of aluminum, chromium, iron, and nickel. However, a correction for 
hydrolyzable ion concentration was not made in the solvent extraction strip solutions, based on the assumption that the complexant (HEDPA) would prevent hydrolysis during the titration.

Total fluoride concentrations were determined using a specific ion electrode by comparing the potentials measured in sample aliquots with potentials measured in dilutions of a standardized (against sodium hydroxide) hydrofluoric acid solution. Spike recovery corrections were then determined by adding additional hydrofluoric acid and again measuring the electrode potential. All potential measurements were made in 3.7-fold dilutions of TISAB-III, a complexant-containing ionic strength buffer obtained from the Orion company, to ensure constant conditions and to assist in making all fluoride available for detection. In addition, sample sizes were chosen to give low $\left(\leq-10^{-5}\right.$ M) fluoride concentrations in the analytical solutions to minimize the fraction of fluoride that was present as complexes. Also, the anaiytical solutions were heated at $-80^{\circ} \mathrm{C}$ overnight to minimize the chance that kinetically inert zirconium-fluoride complexes, as had been observed in some of our recent work, would bias the results; these heated analytical solutions were adjusted back to their initial weight (by adding water) before the potential measurements were made. 


\subsection{RESULTS AND DISCUSSION}

The processing steps to be tested in this experiment were representative, as best as could be done in simple batch contact experiments, of the conditions resulting from the flowsheet depicted in figure 4.1. The steps included 1) sludge dissolution, 2) solution clarification (filtration), 3) feed adjustment, 4) extraction, 5) scrubbing (with three different streams), 6) stripping, and 7) solvent washing. The functions of the three different scrub streams were to 1) remove extracted zirconium (and fluoride) with oxalic acid, 2) remove extracted oxalic acid with nitric acid, and 3) remove extracted nitric acid with water. In retrospect, the use of the second scrub stream was probably not necessary.

The concentrations of zirconium and other dissolved sludge components used here were selected to minimize potential problems such as precipitation of components from aging feed solutions and formation of solid materials that collect at the interface (termed interfacial crud) in the first extraction step. The conditions used did avoid these problems in this experiment; however, these problem areas remain the subject of ongoing study.

\subsection{DISSOLUTION RESULTS}

The density of the mixture (dissolved sludge solution plus undissolved residue) remaining at the end of the dissolution step was estimated to be $1.14 \mathrm{~g} / \mathrm{mL}$. The density of the dissolved sludge solution filtrate plus a small fraction $(\leq 8.7 \%)$ of dilute acid rinse was estimated to be $1.09 \mathrm{~g} / \mathrm{mL}$. This difference $(-5 \%)$ is within the uncertainties in the volume estimations.

The dissolved sludge solution filtrate plus rinse was found to contain $1.14 \underline{\mathrm{M} \mathrm{Na}}, 0.163 \underline{\mathrm{M}} \mathrm{Zr}, 0.57 \underline{\mathrm{M} \mathrm{F}}$, and $1.75 \underline{\mathrm{M} \mathrm{H}}$. Assuming that half of the dilute acid rinse was retained by the filter rather than being present in the mixed solution, it is calculated that the dissolved sludge solution itself contained $1.19 \mathrm{M} \mathrm{Na}, 0.170 \mathrm{M} \mathrm{Zr}, 0.60 \mathrm{M} \mathrm{F}$, and $1.82 \mathrm{M} \mathrm{H}$. These acid concentrations do not agree very well with those calculated from that found in the solvent extraction feed solution and the additions used in that dilution; the calculated values are $2.08 \mathrm{M} \mathrm{H}$ in the mixed filtrate plus rinse and $2.16 \mathrm{M} \mathrm{H}$ 


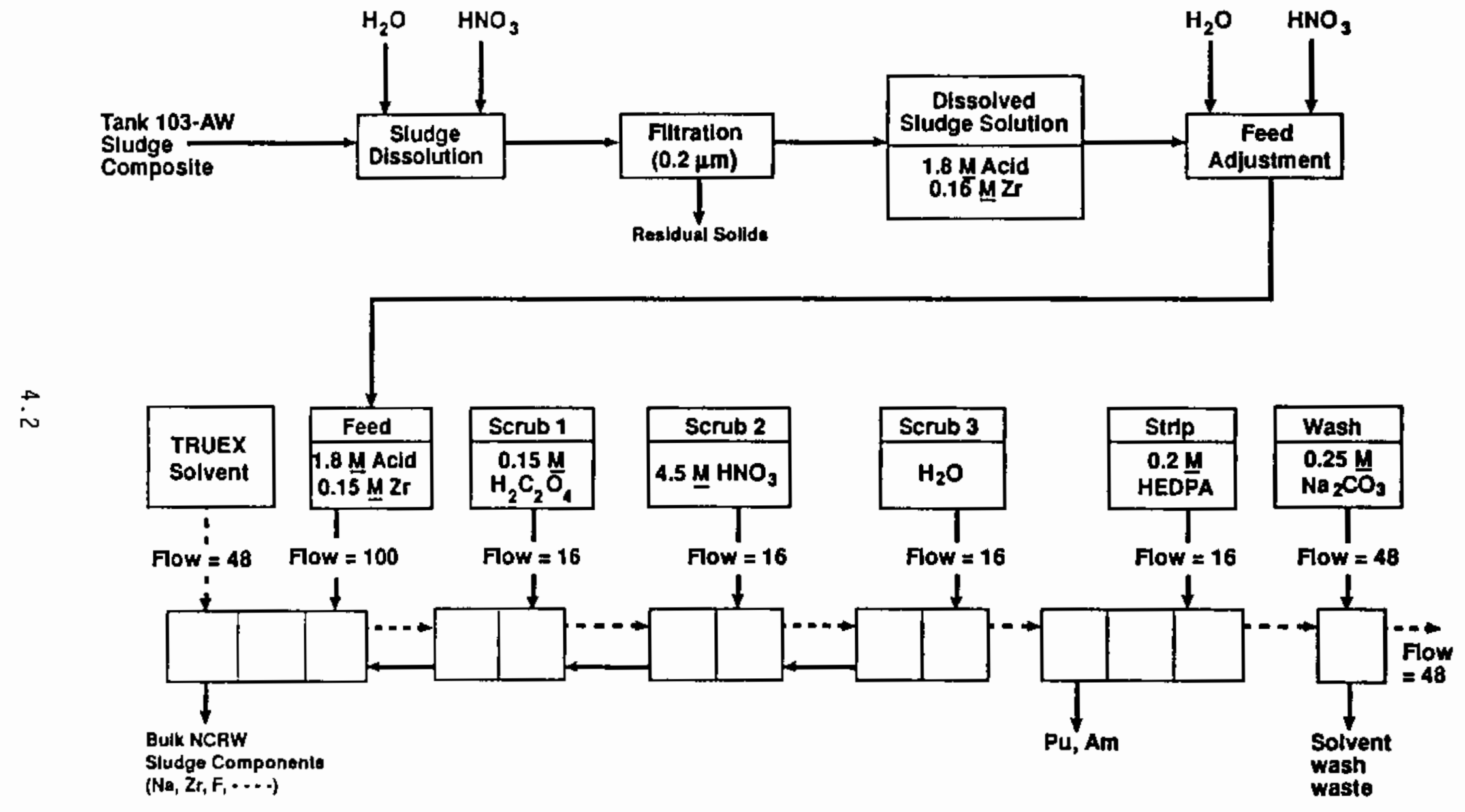

3910:041PF

FIGURE 4.1. Flowsheet Simulated in Design Basis Experiment 
in the dissolved sludge solution itself. These differences are unimportant to the overall objectives of this experiment.

The total amounts of nonradioactive metals found in this NCRW sludge sample and the distribution of these metals in the dissolution, filtration, and washing steps are listed in Table 4.1. Sunmarized in Table 4.1 are the weights found in the three fractions (dissolved sludge solution, wash of residue and filter, and residue from the dissolution step), the total found for each metal, the total per gram of dried sludge, the percentage of each metal that was found in the residue, and the ratio of the concentrations found in the combined water wash solutions to those found in the dissolved sludge solution. Table 4.2 contains the same type of data for alpha- and gamma-emitting radionuclides.

The concentration ratios between the wash and the dissolved sludge solution were generally $-0.02 \pm \sim 0.005$ for the major metallic ion components and the radionuclides. Most, if not all, of these materials found in the wash solution probably came from dissolved sludge solution that remained behind in the filter assembly reservoir when that solution was poured out. The constancy of this ratio between the wash and the dissolved sludge solution indicates that no water-soluble saits of these materials were present in solid form after the dilute acid rinse of the residual solids and the filter assembly. However, the data indicate that some of the minor metallic ion components (calcium, copper, phosphorus, lead, strontium) may have been partially present in water-soluble salts.

The percentages of radionuclides that were found in the undissolved residue were generally $<3 \%$ (Table 4.2 ), and the percentages of metal ions that were found in the undissolved residue were generally $<5 \%$ (Table 4.1 ). However, markedly higher percentages were found for aluminum (24\%) and phosphorus $(43 \%)$. This makes aluminum the major component of the undissolved residue, followed (on a weight basis) by zirconium and then phosphorus. The molar 
IABLE 4.1. Distribution of Nonradioactive Metals in Sludge Dissolution Step

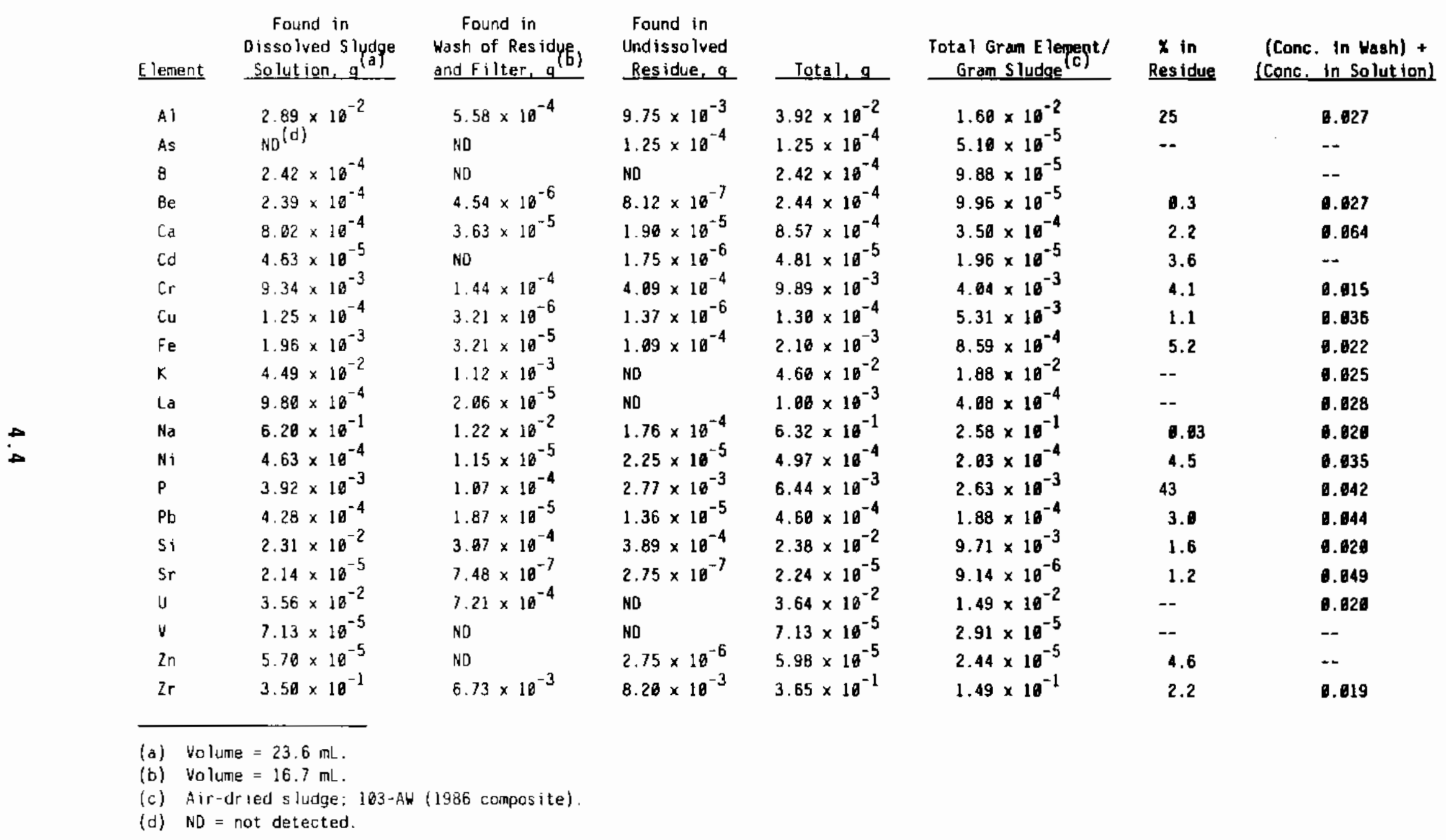


IABLE 4.2. Distribution of Radionuclides in Sludge Dissolution Step

\begin{tabular}{|c|c|c|c|c|c|c|c|}
\hline Radionuc lide & $\begin{array}{l}\text { Found in } \\
\text { Dissolved Sludge } \\
\text { solution, nCi } \\
\end{array}$ & $\begin{array}{l}\text { Found in } \\
\text { Wash of Residue } \\
\text { and Filter, nCi }\end{array}$ & $\begin{array}{r}\text { Found in } \\
\text { Undisso lved } \\
\text { Residue, n.Ci }\end{array}$ & Total. $\mathrm{nC \textrm {C }}$ & $\begin{array}{l}\text { Total nCif } \\
\text { Gram Sludqe }\end{array}$ & $\begin{array}{c}x \text { In } \\
\text { Residue } \\
\end{array}$ & $\begin{array}{l}\text { (Conc. In Yash) + } \\
\text { (Conc. In Solution) }\end{array}$ \\
\hline Total Alpha & $2.69 \times 10^{3}$ & $4.2 \times 10^{1}$ & $1.5 \times 10^{1}$ & $2.75 \times 10^{3}$ & $1.12 \times 10^{3}$ & 1.3 & 0.022 \\
\hline $60_{\mathrm{CO}}$ & $7.83 \times 10^{2}(6)^{(a)}$ & $1.17 \times 10^{1}(11)$ & $1.66 \times 10^{1}(4)$ & $7.31 \times 16^{2}$ & $2.98 \times 10^{2}$ & 2.3 & 9.823 \\
\hline${ }^{166_{R u}}$ & $8.68 \times 10^{3}$ & $1.46 \times 10^{2}$ & $1.07 \times 10^{2}$ & $8.93 \times 16^{3}$ & $3.65 \times 10^{3}$ & 2.9 & 8.624 \\
\hline $125_{\mathrm{Sb}}$ & $1.55 \times 10^{4}\{3\}$ & $2.89 \times 10^{2}(6)$ & $3.8 \times 10^{1}(9)$ & $1.58 \times 10^{4}$ & $6.46 \times 10^{3}$ & 9.2 & 0.026 \\
\hline${ }^{134} \mathrm{Cs}$ & $1.11 \times 10^{3}(5)$ & $2.50 \times 10^{1}(10)$ & $5.12 \times 10^{\circ}(8)$ & $1.14 \times 10^{3}$ & $1.65 \times 10^{3}$ & 9.4 & 0.032 \\
\hline${ }^{137} \mathrm{Cs}$ & $3.78 \times 10^{5}(0.3)$ & $7.82 \times 10^{3}(9.5)$ & $1.71 \times 10^{3}(0.4)$ & $3.80 \times 10^{5}$ & $1.55 \times 10^{5}$ & 3.4 & 0.030 \\
\hline${ }^{144} \mathrm{Ce}$ & $5.38 \times 10^{3}(12)$ & $6.53 \times 10^{1}(36)$ & $1.71 \times 10^{1}(24)$ & $5.46 \times 10^{3}$ & $2.23 \times 10^{3}$ & 6.3 & 0.017 \\
\hline${ }^{154}{ }_{\mathrm{Eu}}$ & $4.83 \times 10^{2}(12\}$ & $\mathrm{NO}{ }^{(\mathrm{b})}$ & ND & $4.83 \times 10^{2}$ & $1.97 \times 10^{2}$ & $\cdots$ & -- \\
\hline $155_{\mathrm{Eu}}$ & $7.17 \times 10^{2}(19)$ & $1.74 \times 10^{1}(32)$ & ND & $7.34 \times 10^{2}$ & $3.90 \times 10^{2}$ & -- & 0.834 \\
\hline${ }^{241}{ }_{\text {Ant }}$ & $4.16 \times 10^{2}(39)$ & NO & ND & $4.16 \times 10^{2}$ & $1.70 \times 10^{2}$ & -- & $\cdots$ \\
\hline
\end{tabular}

(a) Values in parentheses are percentage, one-sigma counting uncertainties.

(b) NO = not detected 
quantities of zirconium and phosphorus in this undissolved residue were identical; whether this is indicative of compound formation is uncertain at this time.

Additional data regarding the undissolved residue from the dissolution step are given in Table 4.3, where the quantities of metals found in the

TABLE 4.3. Composition of Undissolved Residue Relative to Glass Plant Feed Specifications

\begin{tabular}{|c|c|c|c|}
\hline \multirow[b]{2}{*}{ Oxides } & \multirow[b]{2}{*}{ Gram in Residue $(a)$} & \multicolumn{2}{|c|}{$\begin{array}{l}\text { Gram/100 Gram } \\
\text { of Metal Oxides }\end{array}$} \\
\hline & & In Residue & Feed Spec (t) \\
\hline $\mathrm{A}_{2} \mathrm{O}_{3}$ & $1.84 \times 10^{-2}$ & 59 & 26 \\
\hline 2 & $2.66 \times 10^{-5}$ & 0.08 & 20 \\
\hline $\mathrm{Cd} 0$ & $2.00 \times 10^{-6}$ & 0.006 & 10 \\
\hline $\mathrm{Cr}_{2} \mathrm{O}_{3}$ & $5.98 \times 10^{-4}$ & 1.9 & 2 \\
\hline $\mathrm{Fe}_{2} \mathrm{O}_{3}$ & $1.56 \times 10^{-4}$ & 0.50 & 60 \\
\hline $\mathrm{Na}_{2} \mathrm{O}$ & $2.37 \times 10^{-4}$ & 0.76 & 22 \\
\hline $\mathrm{NiO}$ & $2.86 \times 10^{-5}$ & 0.09 & 8 \\
\hline $\mathrm{SiO}_{2}$ & $8.34 \times 10^{-4}$ & 2.7 & 17 \\
\hline $\mathrm{ZrO}_{2}$ & $1.11 \times 10^{-2}$ & 35 & 40 \\
\hline Other oxides & $2.46 \times 10^{-5}$ & 0.08 & 5 \\
\hline $\begin{array}{l}\text { Total metal } \\
\text { oxides }\end{array}$ & $3.14 \times 10^{-2}$ & $\mathrm{NA}(\mathrm{C})$ & $\mathrm{NA}(\mathrm{C})$ \\
\hline & $4.5 \times 10^{-4(d)}$ & 1.4 & 7 \\
\hline $\mathrm{P}_{2} \mathrm{O}_{5}$ & $6.34 \times 10^{-3}(\mathrm{e})$ & 20 & 4 \\
\hline $\mathrm{SO}_{3}$ & $<1.3 \times 10^{-3}$ & $<0.4$ & 2 \\
\hline TOC & $1.4 \times 10^{-4}$ & 0.46 & 11 \\
\hline
\end{tabular}

(a) For $2.45 \mathrm{~g}$ of air-dried sludge.

(b) Preliminary guidance for the maximum allowed in the feed to the proposed Hanford Waste Vitrification Plant, from Westinghouse Hanford.

(c) $N A=$ not applicable.

(d) This amounts to $0.18 \%$ of the fluoride found in the dissolved sludge solution.

(e) Based on ICP analysis for phosphorus; the value based on ion chromatographic analys is for phosphate is $20 \%$ lower. 
residue are presented as the weight of the indicated oxides. Data for fluoride, sulfate, and TOC are also included; the levels found in this residue are compared with our current guidance regarding the maximum amounts allowed in feeds to the glass plant. These results show that aluminum and phosphorous are the only materials that are present in this residue at concentrations that are higher than those allowed in the feed to the glass plant.

The amount of phosphorus in the undissolved residue is only a small fraction $(\sim 0.1)$ of the amount of phosphorus that would be present in the HEDPA used to strip plutonium and americium in the solvent extraction flowsheet that was used in this experiment, and is thus relatively insignificant in this case. However, subsequent studies are directed at decreasing (or eliminating) the phosphorus content of the strip solution; if this is done, then the phosphorus content of the undissolved residue could indeed be important, and means of minimizing it could be addressed.

Examination of data from previous experiments involving Tank 103-AW sludge composites shows that the amount of phosphate found in the undissolved residue in this experiment was not abnormal. However, the potential importance of these amounts had not been properly considered.

The current plan for the treatment of the undissolved residue from the dissolution step is to transfer it by slurrying with dilute acid. This acidic slurry will then be neutralized with sodium hydroxide (and sodium nitrite will be added) so that the neutralized slurry can be stored in an existing carbon steel tank until it is processed in the glass plant. Similarly, the strip solution from the solvent extraction operation will be neutralized and adjusted for storage. These actions result effectively in dilution of the mixture given in Table 4.3 by $\mathrm{Na}_{2} \mathrm{O}$ for the actual glass plant feed. However, it is not possible to add $\mathrm{Na}_{2} \mathrm{O}$ to the residue found in this experiment and still stay within the indicated feed specifications. This is because the amount of $\mathrm{Na}_{2} \mathrm{O}$ that could be added without exceeding its specification lever gives a dilution factor of only 1.27 , whereas a factor of 2.27 would be required to reach the $\mathrm{Al}_{2} \mathrm{O}_{3}$ specification level and a factor of 5.0 would be required to reach the $\mathrm{P}_{2} \mathrm{O}_{5}$ specification level. Thus, it appears that either 1) dissolution procedures should be modified to improve dissolution of 
aluminum and phosphorus species, 2) glass plant feed specifications should be changed, or 3 ) both of the preceding approaches should be followed in order to minimize the quantity of waste glass that must be produced.

\subsection{SOLVENT EXTRACTION RESULTS}

The feed solution to the first extraction contact had a composition representing a blend of the feed and the three scrub streams shown in Figure 4.1. Portions of both the organic and aqueous phases from this contact were then subjected to additional contacts, as summarized in TabTe 4.4.

Analytical data for extractable materials in these contacts are summarized in Table 4.5. This table lists the concentrations present in the feed and in both phases of each contact, and also gives the distribution coefficient (D) values. Values are tabulated for zirconium, uranium, lanthanum, nitric plus hydrofluoric acids, total fluoride, oxalic acid, total alpha activity (plus a few individual plutonium and americium values), and the

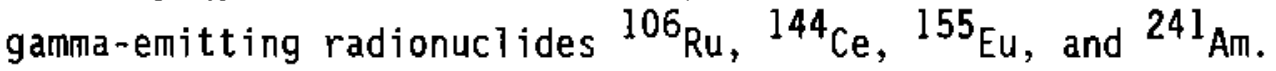

Major conclusions indicated by the data of Table 4.5 include:

- Extraction of alpha-emitting radionuclides was very good; only $-0.1 \mathrm{nCi} / \mathrm{mL}$ of alpha activity remained in the aqueous phase after the third extraction (contact $\mathrm{C}$ ).

- Good separation of alpha-emitting radionuclides from most nonradioactive materials was achieved; the concentrations of zirconium and fluoride relative to the alpha emitters were $-3 \times 10^{-5}$ as large as in the feed, and the relative sodium concentration was even lower.

- Elements that were not well separated from the alpha emitters were uranium and rare earth elements (e.g., lanthanum, cerium, and europium).

As indicated in Table 4.5, only the acid and fluoride concentrations were actually measured in both phases of each contact. In the other cases, only the aqueous phase concentrations were actually determined for each contact and the organic phase concentrations were then calculated from the concentrations found in subsequent contacts and the volume ratios used in those contacts, or, in a few cases, from the difference in the aqueous phase concentrations before and after the contact and the volume ratio. The organic phase 
TABLE 4.4. Solvent Extraction Contacts Performed

\begin{tabular}{|c|c|c|c|c|c|}
\hline Contact & Step & Aqueous Phase & $\begin{array}{c}\text { Organic } \\
\text { Phase }\end{array}$ & $\underline{0 / A^{(a)}}$ & $\begin{array}{l}\text { Organic } \\
\text { vol.. mL }\end{array}$ \\
\hline A & Extn 1 & $\begin{array}{l}\text { Feed (diluted dissolved } \\
\text { sludge solution) }\end{array}$ & $\begin{array}{l}\text { Fresh TRUEX } \\
\text { solvent }\end{array}$ & 0.33 & 8.00 \\
\hline D & Scrub 1 & $1.5 \underline{\mathrm{M}} \mathrm{HNO}_{3}+0.05 \mathrm{M} \mathrm{H} \mathrm{C}_{2} \mathrm{O}_{4}{ }^{(\mathrm{b})}$ & From $A$ & 1.00 & 7.00 \\
\hline E & Scrub 2 & $1.5 \underline{\mathrm{MHNO}} 3+0.05 \mathrm{M} \mathrm{H}_{2} \mathrm{C}_{2} \mathrm{O}_{4}$ & From D & 1.00 & 6.00 \\
\hline$F$ & Scrub 3 & $2.3 \mathrm{M} \mathrm{HNO}_{3}(\mathrm{c})$ & From $\mathrm{E}$ & 1.50 & 5.00 \\
\hline G & Scrub 4 & $2.3 \mathrm{M} \mathrm{HNO}_{3}$ & From $F$ & 1.50 & 4.00 \\
\hline$H$ & Scrub 5 & Water & From $G$ & 3.00 & 3.50 \\
\hline J & Scrub 6 & Water & From $\mathrm{H}$ & 3.00 & 3.00 \\
\hline K & Strip 1 & $0.21 \mathrm{M}$ HEDPA & From $\mathrm{J}$ & 3.00 & 2.50 \\
\hline L & Strip 2 & $0.21 \mathrm{M}$ HEDPA & From $\mathrm{K}$ & 3.00 & 2.00 \\
\hline M & Strip 3 & 0.21 M HEDPA & From L & 3.00 & 1.50 \\
\hline $\mathrm{N}$ & Wash & $0.25 \mathrm{M} \mathrm{Na}_{2} \mathrm{CO}_{3}$ & From $M$ & 1.00 & 1.00 \\
\hline B & Extn 2 & From A & $\begin{array}{l}\text { Fresh TRUEX } \\
\text { solvent }\end{array}$ & 0.33 & 1.00 \\
\hline c & Extn 3 & From B & $\begin{array}{l}\text { Fresh TRUEX } \\
\text { solvent }\end{array}$ & 0.33 & 0.67 \\
\hline
\end{tabular}

(a) $0 / A=$ (volume of organic phase) $\div$ (volume of aqueous phase).

(b) Composition represents a blend of the three scrub streams shown in Figure 1.

(c) Composition represents a blend of the second and third scrub streams shown in Figure 1.

samples from each contact were not submitted for analysis of all components because of the limited capacity of the analytical laboratory and because previous work had demonstrated the value of the "material balance" approach to estimating organic phase concentrations.

The actual material balance values for acid and fluoride in each of the contacts are listed in Table 4.6; these values are seen to be quite good 
TABLE 4.5. Solvent Extraction Results

Molarity

\begin{tabular}{|c|c|c|c|c|c|c|c|c|}
\hline \multirow{2}{*}{ Contact } & \multirow{2}{*}{\multicolumn{2}{|c|}{ Step }} & \\
\hline & & & $\mathrm{Zr}$ & U & La & $\begin{array}{c}\mathrm{HNO}_{3} \mathrm{~Pa}^{\mathrm{H}} \\
\end{array}$ & $\mathrm{F}$ & $\underline{\mathrm{H}}_{2} \underline{\mathrm{C}}_{2} \underline{\mathrm{O}}_{4} \stackrel{\text { (b) }}{\underline{\text { b }}}$ \\
\hline$\ldots$ & Feed & & $1.01 \times 10^{-1}$ & $3.68 \times 10^{-3}$ & $2.00 \times 10^{-4}$ & 1.68 & $3.7 \times 10^{-1}$ & $9.9 \times 10^{-3}$ \\
\hline A & Extn 1 & $\begin{array}{l}\text { Org } \\
A q \\
D\end{array}$ & $\begin{array}{l}2.21 \times 10^{-2(d)} \\
9.89 \times 10^{-2} \\
0.22\end{array}$ & $1.18 \times 10^{-2(d)}$ & $\begin{array}{l}4.04 \times 10^{-4(d)} \\
4.8 \times 10^{-5} \\
8.4\end{array}$ & $\begin{array}{l}0.62 \\
1.36 \\
0.46\end{array}$ & $\begin{array}{l}4.2 \times 10^{-2} \\
3.4 \times 10^{-1} \\
0.12\end{array}$ & $\begin{array}{l}4.9 \times 10^{-3} \\
8.3 \times 10^{-3} \\
0.6\end{array}$ \\
\hline D & Scrub 1 & $\begin{array}{l}\text { Org } \\
A q \\
D\end{array}$ & $\begin{array}{l}2.46 \times 10^{-3(d)} \\
1.96 \times 10^{-2} \\
0.13\end{array}$ & $1.18 \times 10^{-2(d)}$ & $\begin{array}{l}3.56 \times 10^{-4(d)} \\
4.8 \times 10^{-5} \\
7.4\end{array}$ & $\begin{array}{l}0.67 \\
1.51 \\
0.44\end{array}$ & $\begin{array}{l}6.2 \times 10^{-3} \\
3.7 \times 10^{-2} \\
0.17\end{array}$ & $\begin{array}{l}1.8 \times 10^{-2} \\
3.7 \times 10^{-2} \\
0.5\end{array}$ \\
\hline $\mathrm{E}$ & Scrub 2 & $\begin{array}{l}\text { Org } \\
\text { Aq } \\
D\end{array}$ & $\begin{array}{l}\sim 8 \times 10^{-5(d)} \\
2.38 \times 10^{-3} \\
0.03\end{array}$ & $1.18 \times 10^{-2(d)}$ & $\begin{array}{l}3.21 \times 10^{-4(d)} \\
3.5 \times 10^{-5} \\
9.2\end{array}$ & $\begin{array}{l}0.69 \\
1.65 \\
0.42\end{array}$ & $\begin{array}{l}1.6 \times 10^{-3} \\
5.4 \times 10^{-3} \\
0.30\end{array}$ & $\begin{array}{l}2.3 \times 10^{-2} \\
4.6 \times 10^{-2} \\
0.5\end{array}$ \\
\hline $\mathrm{F}$ & Scrub 3 & $\begin{array}{l}\text { Org } \\
\text { Aq } \\
\text { D }\end{array}$ & $\begin{array}{l}-2 \times 10^{-5(d)} \\
9.3 \times 10^{-5} \\
0.2\end{array}$ & $1.18 \times 10^{-2(d)}$ & $\begin{array}{l}3.03 \times 10^{-4(d)} \\
2.7 \times 10^{-5} \\
11.2\end{array}$ & $\begin{array}{l}0.79 \\
1.85 \\
0.43\end{array}$ & $\begin{array}{l}7.4 \times 10^{-4} \\
1.4 \times 10^{-3} \\
0.53\end{array}$ & $\begin{array}{l}7.1 \times 10^{-3} \\
2.4 \times 10^{-2} \\
0.3\end{array}$ \\
\hline G & Scrub 4 & $\begin{array}{l}\text { Org } \\
\mathrm{Aq} \\
\mathrm{D}\end{array}$ & $\sim 9 \times 10^{-6}$ & $1.18 \times 10^{-2(d)}$ & $\begin{array}{l}2.83 \times 10^{-4(d)} \\
3.0 \times 10^{-5} \\
9.4\end{array}$ & $\begin{array}{l}0.80 \\
2.22 \\
0.36\end{array}$ & $\begin{array}{l}3.6 \times 10^{-4} \\
6.4 \times 10^{-4} \\
0.56\end{array}$ & $\begin{array}{l}1.6 \times 10^{-3} \\
8.2 \times 10^{-3} \\
0.2\end{array}$ \\
\hline H & Scrub 5 & $\begin{array}{l}\text { Org } \\
\text { Aq } \\
\text { D }\end{array}$ & $-9 \times 10^{-6}$ & $1.18 \times 10^{-2(d)}$ & $\begin{array}{l}2.73 \times 10^{-4(d)} \\
2.8 \times 10^{-5} \\
9.8\end{array}$ & $\begin{array}{l}0.47 \\
1.15 \\
0.41\end{array}$ & $\begin{array}{l}3.1 \times 10^{-4} \\
1.5 \times 10^{-4} \\
2.1\end{array}$ & $\begin{array}{l}1.2 \times 10^{-3} \\
1.4 \times 10^{-3} \\
0.8\end{array}$ \\
\hline $\mathrm{J}$ & Scrub 6 & $\begin{array}{l}\text { Org } \\
\mathrm{Aq} \\
\mathrm{D}\end{array}$ & $-7 \times 10^{-6}$ & $1.18 \times 10^{-2(d)}$ & $\begin{array}{l}2.61 \times 10^{-4(d)} \\
3.8 \times 10^{-5} \\
6.9\end{array}$ & $\begin{array}{l}0.27 \\
0.67 \\
0.40\end{array}$ & $\begin{array}{l}2.8 \times 10^{-4} \\
>9 \times 10^{-5} \\
>3\end{array}$ & $\begin{array}{l}9.5 \times 10^{-4} \\
6.0 \times 10^{-4} \\
1.6\end{array}$ \\
\hline $\mathrm{k}$ & Strip 1 & $\begin{array}{l}\text { Org } \\
\text { Aq } \\
\text { D }\end{array}$ & $-2 \times 10^{-5}$ & $\begin{array}{l}4.67 \times 10^{-4(d)} \\
3.41 \times 10^{-2} \\
0.014\end{array}$ & $\begin{array}{l}6.7 \times 10^{-6(d)} \\
7.62 \times 10^{-4} \\
0.009\end{array}$ & $\begin{array}{l}0.16 \\
0.36 \\
0.44\end{array}$ & $\begin{array}{l}2.0 \times 10^{-4} \\
1.3 \times 10^{-4} \\
1.5\end{array}$ & \\
\hline
\end{tabular}


TABLE 4.5. (contd)

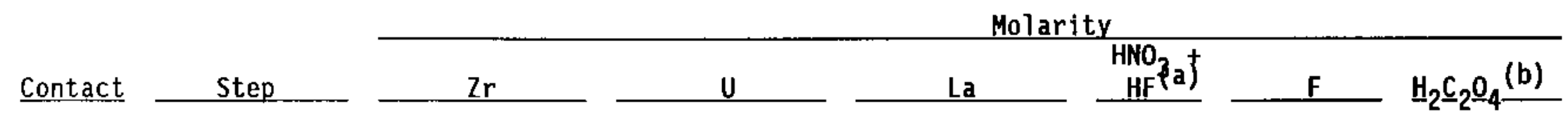

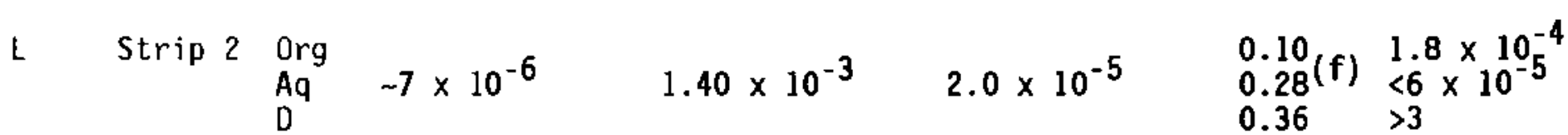

$$
\begin{aligned}
& \text { M Strip } 3 \quad \begin{array}{l}
\text { Org } \\
\text { Aq } \\
D
\end{array} \\
& \begin{array}{ll}
N \quad \text { Wash } & \text { Org } \\
& \text { Aq } \\
\text { D }
\end{array}
\end{aligned}
$$

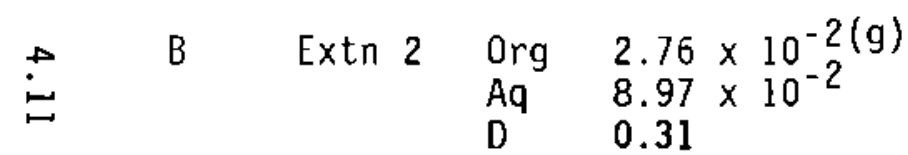

$$
\begin{aligned}
& \begin{array}{cll}
\text { C Extn 3 } & \text { Org } & 2.19 \times 010^{-2(9)} \\
& \text { Aq } & 8.24 \times 10^{-2} \\
& \text { D } & 0.27
\end{array} \\
& \begin{array}{ll}
0.04(f) & 1.4 \times 10^{-4} \\
0.19(f) & <6 \times 10^{-5} \\
0.2 & >2 \\
& <7 \times 10^{-6} \\
& 2.0 \times 10^{-4} \\
& <0.04
\end{array} \\
& \begin{array}{lll}
0.62 & 4.2 \times 10^{-2} & 5.7 \times 10^{-3} \\
1.05 & 3.6 \times 10^{-1} & 6.4 \times 10^{-3} \\
0.59 & 0.12 & 0.9 \\
& & \\
0.58 & 3.5 \times 10^{-2} & 5.4 \times 10^{-3} \\
0.87 & 3.5 \times 10^{-1} & 4.5 \times 10^{-3} \\
0.67 & 0.10 & 1.2
\end{array}
\end{aligned}
$$


IABLE 4.5. (contd)

\begin{tabular}{|c|c|c|c|c|c|c|c|c|c|}
\hline \multirow[b]{2}{*}{ Contact } & \multirow{2}{*}{\multicolumn{2}{|c|}{ Step }} & \multicolumn{3}{|c|}{ Alpha, $\mathrm{nCi} / \mathrm{mL}$} & \multicolumn{4}{|c|}{ Gamma, nCi/mL } \\
\hline & & & Total & $\mathrm{Pu}$ & $\mathrm{Am}$ & ${ }^{106} \mathrm{Ru}$ & ${ }^{144} \mathrm{Ce}$ & ${ }^{155} \mathrm{Eu}$ & $241_{\mathrm{Am}}$ \\
\hline$\cdots$ & Feed & & $71.4(4)^{(c)}$ & 62.0 & 9.5 & $221(12)$ & $118(18)$ & $13.7(34)$ & $15(41)$ \\
\hline A & Extn 1 & $\begin{array}{l}\mathrm{Org} \\
\mathrm{Aq}(\mathrm{e})\end{array}$ & $\begin{array}{l}209^{(d)} \\
3.05(8) \\
69\end{array}$ & & & $\begin{array}{l}28.3^{(d)} \\
229(11) \\
0.12\end{array}$ & $347^{(d)}$ & $51.8^{(d)}$ & $37.0^{(\mathrm{d})}$ \\
\hline D & Scrub 1 & $\begin{array}{l}\text { Org } \\
\text { Aq } \\
\text { D }\end{array}$ & $\begin{array}{l}205^{(d)} \\
4.66(6) \\
44\end{array}$ & & & $\begin{array}{l}17.3^{(d)} \\
11.0(18) \\
1.6\end{array}$ & $\begin{array}{l}318^{(d)} \\
29.3(10) \\
11\end{array}$ & $\begin{array}{l}46.1^{(d)} \\
5.70(14) \\
8.1\end{array}$ & $\begin{array}{l}34.1^{(d)} \\
2.9(33) \\
12\end{array}$ \\
\hline E & Scrub 2 & $\begin{array}{l}\mathrm{Org} \\
\mathrm{Aq} \\
\mathrm{D}\end{array}$ & $\begin{array}{l}198^{(d)} \\
6.94(9) \\
28\end{array}$ & & & $\begin{array}{l}12.5(\mathrm{~d}) \\
4.79(21) \\
2.6\end{array}$ & $\begin{array}{l}296^{(d)} \\
21.3(6) \\
14\end{array}$ & $\begin{array}{l}42.2^{(d)} \\
3.94(30) \\
11\end{array}$ & $\begin{array}{l}32.4^{(\mathrm{d})} \\
1.7^{(20)} \\
19\end{array}$ \\
\hline $\mathrm{F}$ & Scrub 3 & $\begin{array}{l}\text { Org } \\
\mathrm{Aq} \\
\mathrm{D}\end{array}$ & $\begin{array}{l}196^{(d)} \\
2.02(10) \\
97\end{array}$ & & & $\begin{array}{l}8.69(d) \\
5.72(16) \\
1.5\end{array}$ & $\begin{array}{l}284(\mathrm{~d}) \\
18.0(8) \\
16\end{array}$ & $\begin{array}{l}40.5(d) \\
2.52(11) \\
16\end{array}$ & $\begin{array}{l}30.9^{(\mathrm{d})} \\
2.2^{2(19)} \\
14^{(19)}\end{array}$ \\
\hline G & Scrub 4 & $\begin{array}{l}\text { Org } \\
\text { Aq } \\
\text { D }\end{array}$ & $\begin{array}{l}195^{(d)} \\
1.46(6) \\
134\end{array}$ & & & $\begin{array}{l}6.84(\mathrm{~d}) \\
2.78(32) \\
2.5\end{array}$ & $\begin{array}{l}267^{(d)} \\
16.3(8) \\
16\end{array}$ & $\begin{array}{l}38.7^{(d)} \\
2.7^{2(13)} \\
14\end{array}$ & $\begin{array}{l}30.0^{(d)} \\
1.4(27)\end{array}$ \\
\hline$H$ & Scrub 5 & $\begin{array}{l}\text { Org } \\
\mathrm{Aq} \\
\mathrm{D}\end{array}$ & $\begin{array}{l}195^{(d)} \\
2.54(8) \\
76^{(8)}\end{array}$ & & & $6.84^{(d)}$ & $\begin{array}{l}262^{(d)} \\
15.1(8) \\
17\end{array}$ & $\begin{array}{l}37.6^{(d)} \\
3.29(9) \\
11\end{array}$ & $\begin{array}{l}29.2^{(d)} \\
2.3^{(19)} \\
13\end{array}$ \\
\hline J & Scrub 6 & $\begin{array}{l}\text { Org } \\
\mathrm{Aq} \\
\mathrm{D}\end{array}$ & $\begin{array}{l}193^{(d)} \\
5.03(5) \\
38\end{array}$ & & & $6.84^{(d)}$ & $\begin{array}{l}254(\mathrm{~d}) \\
24.3(6) \\
10\end{array}$ & $\begin{array}{l}35.9^{(d)} \\
4.95(7) \\
7.2\end{array}$ & $\begin{array}{l}28.4^{(d)} \\
2.5(16) \\
11\end{array}$ \\
\hline K & Strip 1 & $\begin{array}{l}\mathrm{Org} \\
\mathrm{Aq} \\
\mathrm{D}\end{array}$ & $\begin{array}{l}1.57^{(d)} \\
574(5) \\
0.0027\end{array}$ & $\begin{array}{l}0.34^{(d)} \\
516 \\
0.0007\end{array}$ & $\begin{array}{l}1.09(d) \\
54 \\
0.020\end{array}$ & $6.84^{(d)}$ & $\begin{array}{l}14.3^{(d)} \\
718(2) \\
0.020\end{array}$ & $\begin{array}{l}0.93 \text { (d) } \\
105(2) \\
0.009\end{array}$ & $\begin{array}{l}1.07(d) \\
82(5) \\
0.013\end{array}$ \\
\hline
\end{tabular}


IABLE 4.5. (contd)

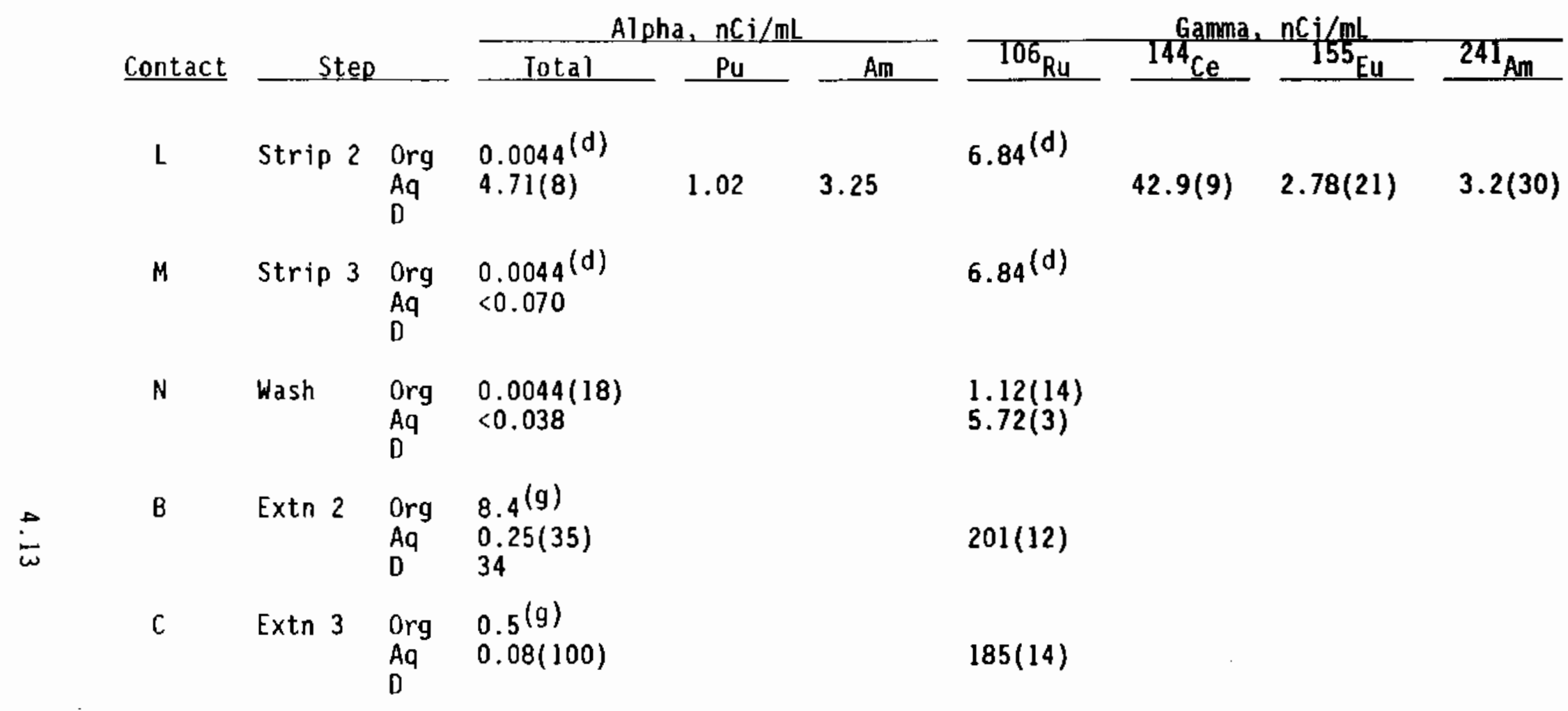

(a) Based on titration to $\mathrm{pH}=7$ (except for strip solutions) and correction for the contribution of hydrolyzable metal ions and oxalic acid (if present).

(b) Calculated from amounts added and distribution coefficients given by Horwitz et al. (1985).

(c) Values enclosed by parentheses are percentage, one-sigma counting uncertainties.

(d) Values obtained by material balance from the concentrations found in subsequent contacts and the volume ratios used in those contacts.

(e) $D=$ distribution coefficient (equals concentration in organic phase divided by concentration in aqueous phase).

(f) Based on titration to $\mathrm{pH}=5$, minus that found for HEDPA $(0.427 \mathrm{M})$.

(g) Values obtained from the difference in the aqueous phase concentration before and after the contact and the volume ratio used in the contact. 
(generally within $\pm 10 \%$ ). Also listed in this table is a comparison of the fluoride concentrations that were actually found in the organic phase with those calculated as discussed in the preceding paragraph; this comparison illustrates the validity of the "material balance" approach to deducing the organic phase concentrations.

Additional support for the overall validity of the data given in Table 4.6 comes from the material balance comparisons between the amounts found in the aqueous phases of the first extraction contact plus the scrub, strip, and wash contacts and the amounts analyzed in the feed. These balances were $105 \%$ for zirconium, $107 \%$ for uranium, $91 \%$ for 1 anthanum, $96 \%$ for fluoride, $102 \%$ for total alpha, $108 \%$ for ruthenium, $98 \%$ for cerium, $126 \%$ for europium, and $82 \%$ for americium; these agreements are considered to be excellent.

TABLE 4.6. Acid and Fluoride Material Balances in Solvent Extraction Contacts

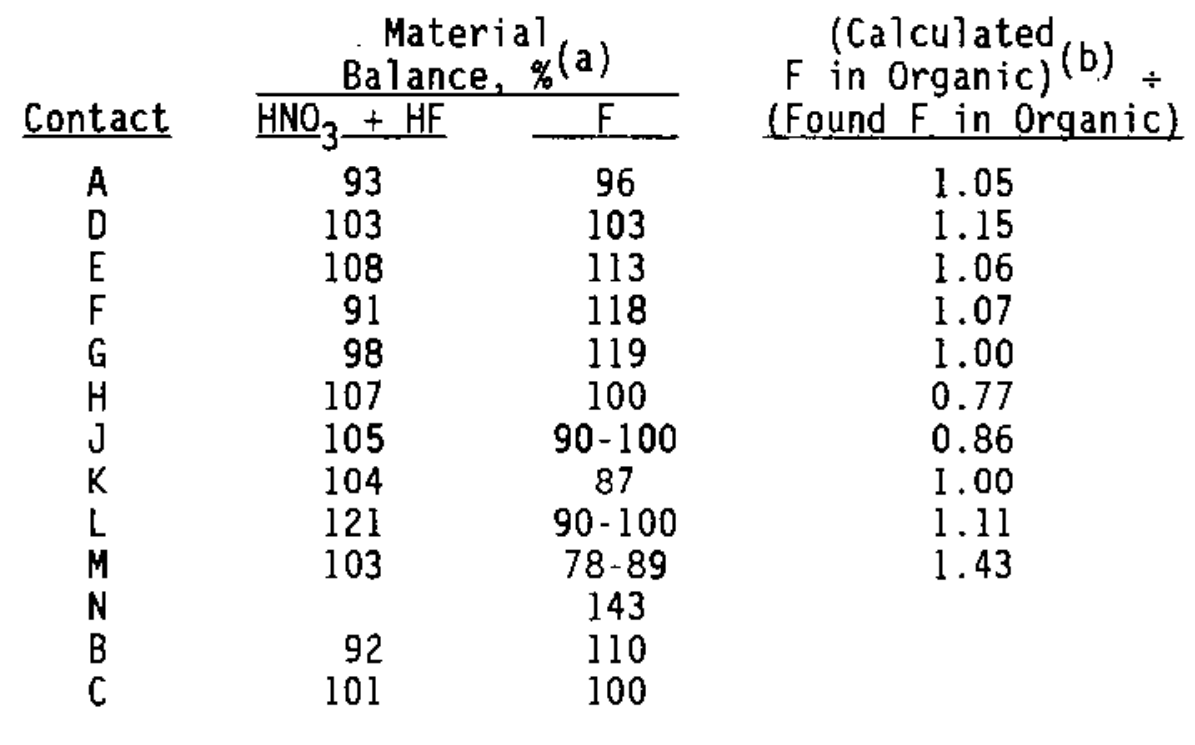

(a) Moles found in the two phases after contact relative to moles found in input to contact.

(b) Calculated fluoride in organic based on amounts found in the aqueous phases of subsequent contacts. 
Zirconium distribution coefficients of $0.22,0.31$, and 0.27 are listed in Table 4.5 for the three extraction steps. However, somewhat different values are calculated from the ratios of zirconium to sodium in the aqueous phases before and after each of the three extractions (and the volume ratios); these distribution coefficient values are $0.27,0.24$, and 0.22 , respectively. It appears to be safe to say that the zirconium distribution coefficient did not vary markedly in the three extraction contacts.

Uranium distribution coefficients were too high to measure (by the procedures used) in all contacts except the first strip (contact $K$ ). Lanthanum distribution coefficient values near 10 were observed in the first extraction and in all six of the scrub contacts. As expected, distribution coefficients

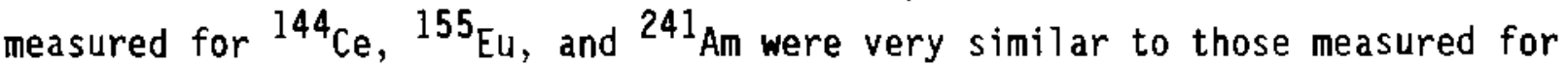
lanthanum.

Where comparison is possible, very good agreement was found between ${ }^{241}$ Am measured by alpha energy analysis and by gamma counting. Because the plutonium alpha activity was higher than the americium alpha activity and because the distribution coefficients for total alpha activity were greater

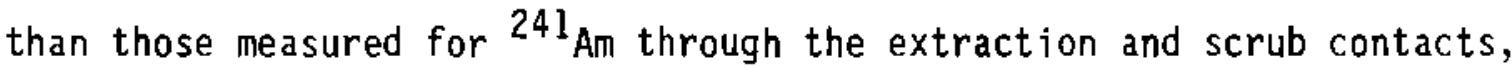
plutonium distribution coefficients in those contacts must have been greater than americium distribution coefficients in those contacts. This indicates that plutonium was not present as a trivalent ion in the feed solution. The fact that the plutonium distribution coefficient in the (complexantcontaining) strip contact $K$ is markedly lower than those for both (trivalent) americium and (hexavalent) uranium indicates that plutonium was present in a tetravalent form. This is consistent with known plutonium chemistry.

The behavior of ruthenium was unusual, which is not surprising for this element. Its distribution coefficient in the first extraction contact (A) was only $\sim 0.1$, but much higher distribution coefficients prevailed through the scrub and strip contacts. Approximately $1 \%$ of the ${ }^{106}$ Ru that was present in the feed remained in the organic phase after the strip contacts; of that amount, $84 \%$ was removed in the solvent wash step (contact $N$ ).

The behavior of fluoride in the solvent extraction contacts was also unusual in that much of the extracted fluoride scrubbed out readily, but $\sim 1 \%$ 
of that extracted remained in the organic after the scrub contacts, and $~ 50 \%$ of that remained after the strip contacts. However, the carbonate wash step effectively removed fluoride from the organic phase. The fluoride contained in the strip solutions amounted to $-0.006 \%$ of that in the feed. This is small relative to the $0.18 \%$ found in the undissolved residue (Table 4.4 ); thus, the fluoride content of the strip solution would not appreciably impact the fluoride content of the feed to the glass plant, which will consist of the stripped materials plus the undissolved residue.

Tables 4.7 and 4.8 contain additional data regarding materials present in the aqueous phases of the solvent extraction contacts, in the solvent extraction feed solution, and in the dissolved sludge solution that was

TABLE 4.7. Additional Radionuclide Concentration Data for Solvent Extraction Samples

\begin{tabular}{|c|c|c|c|c|c|c|}
\hline \multirow[b]{2}{*}{ Contact } & \multirow[b]{2}{*}{ Solut ion } & \multicolumn{5}{|c|}{$n C \mathrm{C} / \mathrm{mL}$} \\
\hline & & ${ }^{66} \mathrm{CO}_{0}$ & ${ }^{125} \mathrm{Sb}$ & ${ }^{134} \mathrm{cs}$ & ${ }^{13 /} c_{s}$ & $154{ }_{E u}$ \\
\hline-- & Diss. Sludge & $2.98 \times 10^{1}(6)^{(a)}$ & $6.56 \times 10^{2}(3)$ & $4.70 \times 10^{1}(5)$ & $1.57 \times 10^{4}(0.3)$ & $2.04 \times 10^{1}(12)$ \\
\hline-- & SX Feed & $1.60 \times 10^{1}(12)$ & $3.71 \times 10^{2}(4)$ & $2.77 \times 10^{1}(7)$ & $9.65 \times 10^{3}(0.3)$ & $1.38 \times 10^{1}(16)$ \\
\hline A & Aqueous & $1.50 \times 10^{1}(8)$ & $4.00 \times 10^{2}(4)$ & $2.78 \times 10^{1}(20)$ & $9.78 \times 10^{3}(0.3)$ & \\
\hline 0 & Aqueous & & & & $2.31 \quad(35)$ & \\
\hline$E$ & Aqueous & & & & & \\
\hline$F$ & Aqueous & & & & & \\
\hline G & Aqueous & & & & & $2.0(13)$ \\
\hline H & Aqueous & & & & & \\
\hline J & Aqueous & & & & & \\
\hline k & Aqueous & & & & & $5.12 \times 10^{1}(4)$ \\
\hline$k$ & Aqueous & & & & & \\
\hline M & Aqueous & & & & & \\
\hline N & Aqueous & & & & & \\
\hline B & Aqueous & $1.72 \times 10^{l}(8)$ & $3.57 \times 10^{2}(4)$ & $2.68 \times 19^{1}(7)$ & $9.57 \times 10^{3}(0.3)$ & \\
\hline c & Aqueous & $1.87 \times 10^{1}(7)$ & $3.86 \times 10^{2}(4)$ & $3.19 \times 10^{1}(7)$ & $9.61 \times 10^{3}(0.3)$ & \\
\hline
\end{tabular}

(a) Values in parentheses are percentage, one-sigma counting uncertainties. 


\section{IABLE 4.8. Additional ICP Data for Solvent Extraction Samples}

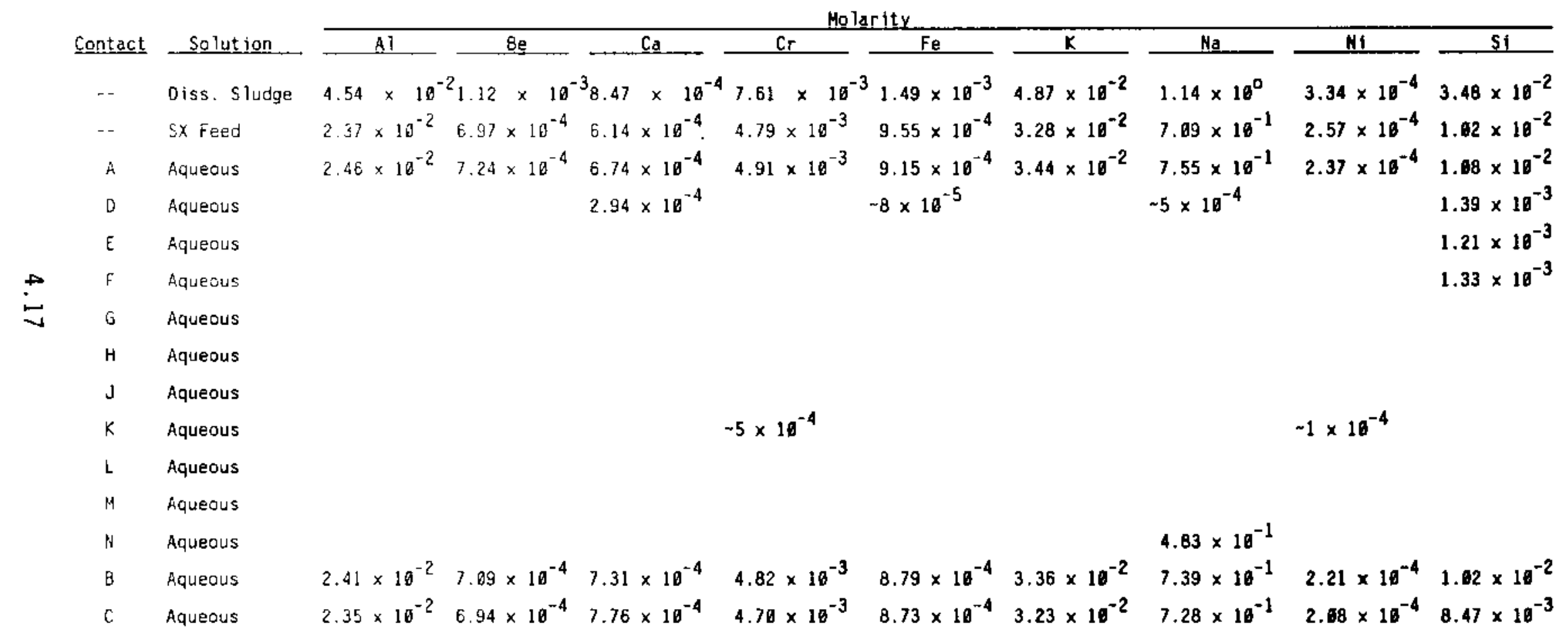


diluted to prepare the feed. These data are presented primarily for completeness, although they do provide some good information in a few areas.

Table 4.7 contains additional radionuclide concentration data and Table 4.8 contains additional ICP analytical data. Elements that were present at $<10^{-4} \underline{M}$ in the dissolved sludge solution were omitted from this table; study of the behavior of many of these elements would require analys is of more concentrated samples than was done here. Phosphorus was also omitted from this table because of its introduction in the solvent, and in the strip solutions, during the contacts.

The fractions of the concentration in the feed solution relative to those in the dissolved sludge solution (Tables 4.7 and 4.8 ) were generally quite close to that expected (0.61) from the volumes used in the dilution step. A notable exception is silicon, where only half as much was found in the feed solution as had been expected from analysis of the dissolved sludge solution shortly after the undissolved residue had been filtered off. This suggests that half of the silicon precipitated in the 2-day interval between filtration and preparation of the feed. Other observations regarding silicon precipitation will be discussed in a future report.

Although there were no significant decreases in their concentrations during the extraction contacts, the presence of calcium, iron, sodium, and ${ }^{137} \mathrm{Cs}$ in the first scrub (contact D) aqueous indicates that these materials were slightly extracted. Assuming that all of these materials that extracted in contact $A$ were scrubbed out in contact $D$, distribution ratios of 0.4 for calcium, 0.09 for iron, 0.0006 for sodium, and 0.0002 for ${ }^{137} \mathrm{Cs}$ were calculated.

The ICP data (Table 4.8) provide an uncertain indication of the presence of chromium and nickel in the first strip solution (contact $K$ ). Accepting the indicated amounts and assuming that no removal of these elements occurred in the scrub steps, distribution coefficient values of 0.03 for chromium and 0.1 for nickel would have prevailed in extraction contact $A$. Such extraction behavior would be quite unique; further study would be required to verify it. 
It is not known whether the silicon concentrations found in the aqueous phases from scrub contacts $\mathrm{D}, \mathrm{E}$, and $\mathrm{F}$ represent silicon that extracted and was then scrubbed out or silicon that appeared because of (partial) dissolution of the glass vials in which the contacts were performed. Material balance considerations indicate that dissolution was important, so no distribution coefficient values for silicon will be estimated here. 



\subsection{REFERENCES}

Horwitz, E. P., D. G. Kalina, H. Diamond, G. F. Vandegrift, and W. W. Schulz. 1985. "The TRUEX Process-A Process for the Extraction of the Transuranic Elements from Nitric Acid Wastes Utilizing Modified PUREX Solvent." Solvent Extraction and Ion Exchange 3(182):75-109.

Swanson, J. L. 1991. Initial Studies of Pretreatment Methods for Neutralized Cladding Removal Haste (NCRW) Sludge. PNL-7716, Pacific Northwest Laboratory, Richland, Washington. 



\section{DISTRIBUTION}

No. of

Copies

OFFSITE

12 DOE/Office of Scientific and Technical Information

\section{ONSITE}

\section{Westinghouse Hanford Company}

J. N. Appel, R2-07

S. A. Barker, R2-07 (3)

W. B. Barton, S6-70

M. A. Cahill, R3-46

M. J. Horhota, S1-53

J. R. Jewett, T6-50

S. S. Lowe, R2-07

D. J. Newland, $\mathrm{Nl}-35$

R. M. Orme, R2-07

D. E. Place, $\$ 6-70$

1 DOE Richland Operations office
No. of

Copies

37 Pacific Northwest Laboratory

B. 0. Barnes, P7-14

G. H. Bryan, P7-25

J. M. Deal, P7-25

R. E. Einziger, P7-14

C. 0. Harvey, P7-22

B. M. Johnson, K5-02

D. E. Kurath, P7-41

W. W. Laity, K2-15

G. J. Lumetta, P7-25

K. A. Parnel1, P7-18

K. H. Pool, P8-44

D. E. Rinehart, P8-41

R. D. Scheele, P7-25

P. A. Scott, P7-43

L. J. Sealock, K2-10

J. L. Swanson, P7-25 (15)

S. W. Thompson, P7-22 Publishing Coordination Technical Report Files (5)

M. Dev, A5-21 
$\cdot$
$\cdot$
$\cdot$
$\cdot$ 